Check for updates

Mental Health - Time for Action Foundation

Twitter @lovebillybragg Cite this as: BMJ 2021;375:n2706 http://dx.doi.org/10.1136/bmj.n2706 Published: 5 November 2021

\section{Underfunded mental healthcare in the NHS: the cycle of preventable distress continues}

\author{
Without early intervention in the community and continuity of care, people with mental health \\ conditions will continue to be failed by services, writes Rachel Bannister
}

\section{Rachel Bannister co-founder and chair}

As a mental health campaigner and chair of the charity Mental health - Time for Action Foundation, I know only too well the challenges facing those experiencing the torments of mental illness within what is arguably a chaotic, severely underfunded, and too often barbaric system of mental healthcare. ${ }^{1}$

When my daughter was first referred for mental health treatment some eight years ago, I believed (naively in retrospect) that NHS services would have all the staffing and resources needed to enable her to work towards a full recovery. Most importantly, I believed that our daughter would, at the very least, experience a continuity of care similar to what she'd received through primary care for the first 13 years of her life.

Little did I know that the weeks of waiting would turn to months and that the individualised, holistic package of care she needed would never materialise. Instead, I was forced to witness her deterioration into crisis, with the then inevitable outcome of admission to an acute hospital-albeit one that was many miles from home.

This absence of early intervention within our local community, alongside a lack of continuity of care, has undoubtedly prolonged my daughter's recovery from an eating disorder and could very well have worsened her prognosis.

Eight years on from the onset of my daughter's illness, few could argue that mental health services are any better equipped today. Years of spending cuts to mental health services since $2010,^{2}$ alongside an increased demand for treatment, has exacerbated the crisis we are now facing.

After 20 months of living through the covid-19 pandemic, it comes as no surprise that child and adolescent mental health services have seen a dramatic increase in referrals. ${ }^{3}$ The number of children and young people waiting for treatment for eating disorders, in particular, has more than tripled, ${ }^{4}$ and services are struggling to meet demand as a consequence. This has led the Royal College of Psychiatrists and other organisations to renew their call for properly funded and staffed mental healthcare services. ${ }^{4}$

We cannot begin to repair and rebuild mental healthcare services until we have enough trained and experienced staff. However, as a recent workforce report from the BMA highlighted, ${ }^{5}$ the stark reality is that staffing has failed to increase in line with demand. These shortages in turn affect staff workload and wellbeing, inevitably leading to some of the most experienced and committed clinicians leaving their posts, and the cycle continuing.

Our family has experienced firsthand the care of many hardworking, talented, and compassionate healthcare professionals. Every day, they face the challenges of working within an underfunded system for no other reason than a desire to provide help and hope to those of us who have had a deterioration in our mental health. But the commitment and dedication of frontline staff has been taken for granted for far too long.

I know how hard my daughter's care coordinator battled to ensure they could offer us the support we needed as a family, while at the same time spending hours trying to secure an inpatient bed. They often confided in me that they hadn't had time to eat lunch or even have a toilet break.

Those in positions of power must heed the warnings of unions and those on the frontline and ensure that pay and working conditions are prioritised as a matter of urgency. ${ }^{6}$ Services can ill afford further losses to the workforce.

Many of us with lived experience of mental ill health and who have spent years advocating for better care are growing disillusioned with mental health awareness campaigns. We are tired of the encouragement to "reach out for help" that isn't there, and weary of the hollow government rhetoric and false assurances (including from Nadine Dorries, who recently declared that children and adolescent services are well resourced ${ }^{7}$ ) when it doesn't match reality.

When I met Jeremy Hunt in his role as health secretary in $2018,{ }^{8}$ he apologised for the absence of local and intensive community based treatment for eating disorders, which led to my daughter being sent over 300 miles for care. He made a commitment that all so called "out of area" admissions would end by 2021. Yet a lack of investment in outpatient services has meant that, three years on, not only have such placements continued, ${ }^{9}$ but that the number of placements where patients were sent more than $300 \mathrm{~km}$ away from their home has almost doubled since $2017 .^{10}$ community when they're at their most vulnerable has a hugely detrimental impact on their recovery, as well as affecting the wider family. The pain and anguish caused by repeated separations from my daughter, latterly over 300 miles from our home, led me to develop an addiction to prescription sleeping
Sending someone miles from their home and 
medication, which ultimately required an emergency admission to an acute mental health ward. ${ }^{11}$ I often reflect how different the past few years would have been for our family had my daughter been able to access the care she needed, early on and while remaining at home with support from her family.

We desperately need to invest in publicly funded mental healthcare that offers a person high quality, early intervention and treatment within their community. When a patient requires more intensive care as my daughter did, an ideal model is a "step-up service.” These provide flexible, individualised care with intensive support in the day for as many hours as are needed, while allowing the individual to continue to live at home amid the support of family and community. The Royal Free Eating Disorders CAMHS service is one example of this, ${ }^{12}$ which has demonstrated good outcomes for such an approach. Services that offer this sort of community care treat patients for a fraction of the cost of an inpatient bed.

With the NHS having to resort to using private mental health beds at a cost of more than $£ 186$ million a year, ${ }^{13}$ it should surely be the government's priority to support the building of robust and well resourced outpatient services. How many more reports of preventable suffering and failed care will it take before we witness transformation of mental healthcare?

Acknowledgment: Rachel Bannister is also a carer representative on the Royal College of Psychiatrists council, Trent executive committee, and Quality Eating Disorders Network (QED), and a patient representative on the general adult faculty of the Royal College of Psychiatrists.

Competing interests: none declared.

1 Autistic teens face 'barbaric' treatment, parents tell MPs. BBC News. 27 April 2021 https://www.bbc.co.uk/news/uk-56905842

2 Trades Union Congress. Breaking Point: the crisis in mental health funding. 19 October 2018. https://www.tuc.org.uk/sites/default/files/Mentalhealthfundingreport2_0.pdf

3 Gregory A. Children's NHS mental health referrals double in pandemic. The Guardian. 23 September 2021. https://www.theguardian.com/society/2021/sep/23/childrens-nhs-mentalhealth-referrals-double-in-pandemic

4 Brennan C. The Royal College of Psychiatrists report on severe strain on eating disorder services. Ment Health Today. 26 August 2021. https://www.mentalhealthtoday.co.uk/news/eating-disorders/the-royal-college-of-psychiatrists-report-on-severe-strain-on-eating-disorder-services.

5 The BMA. Mental health workforce report. 22 April 2021. https://www.bma.org.uk/advice-andsupport/nhs-delivery-and-workforce/workforce/mental-health-workforce-report

6 Campbell D, Elgot J. Starmer calls for NHS 'heroes' to get bigger pay rise after unions attack 'pitiful' 1\%. The Guardian. 4 May 2021. https://www.theguardian.com/society/2021/mar/04/unions-attackpitiful-1-pay-rise-proposed-for-nhs-staff

7 Mooney G. The minister for mental health has straight up denied the UK is in a mental health crisis. The Tab. 21 July 2021. https://thetab.com/uk/2021/07/21/the-minister-for-mental-healthhas-straight-up-denied-the-uk-is-in-a-mental-health-crisis-215779

8 Gillespie J. Anorexic teen wins care apology from Hunt. The Times. 21 January 2018. https://www.thetimes.co.uk/article/anorexic-teen-wins-care-apology-from-hunt-x9tc9dqr2

9 Campbell D. Ministers under fire over breaking of mental health crisis pledge in England. The Guardian. 29 September 2021. https://www.theguardian.com/society/2021/sep/29/ministersunder-fire-over-breaking-of-mental-health-crisis-pledge-in-england

10 Woodcock A. Cuts to NHS mental health beds mean more than $\mathrm{f} 100 \mathrm{~m}$ spent on private providers The Independent. 5 September 2021. https://www.independent.co.uk/news/uk/politics/mentalhealth-nhs-allin-khan-b1914652.html

11 Bannister R. Rachel Bannister on struggling with addiction: "You just need a hand to hold to see you through." BMJ Opinion. 24July 2020. https://blogs.bmj.com/bmi/2020/07/24/rachel-bannisteron-struggling-with-addiction-you-just-need-a-hand-to-hold-to-see-you-through-this/

12 Royal Free London NHS Foundation Trust. Eating disorder service. https://www.royalfree.nhs.uk/services/services-a-z/child-and-adolescent-mental-health-services/eating-disorder-service/

13 NHS spends millions a year on private beds for mental health patients. Nurs Stand. 25June 2019 https://rcni.com/nursing-standard/newsroom/news/nhs-spends-millions-a-year-private-bedsmental-health-patients-150431. 